\title{
Life problems and physical illness as risk factors for suicide in older people: a descriptive and case-control study
}

\author{
DANIEL MICHAEL JAMES HAR WOOD*, KEITH HAWTON, TONY HOPE, \\ LOUISE HARRISS AND ROBIN JACOBY \\ University of Oxford Department of Psychiatry, Warneford Hospital, Oxford, UK
}

\begin{abstract}
Background. The role of physical illness and life problems in contributing to suicide in older people is potentially important with regard to suicide prevention.

Method. The aim of the study was to determine the life problems other than psychiatric illness contributing to suicide in older people. Semi-structured psychological autopsy interviews, covering life problems and physical illness prior to death, were conducted with informants for 100 people aged 60 years old and over who died through suicide in five English counties. Interviews were completed with informants for 54 age- and sex-matched control subjects who died through natural causes.
\end{abstract}

Results. The three most frequent life problems associated with suicide were physical illness, interpersonal problems, and bereavement. Physical health problems were present in $82 \%$ and felt to be contributory to death in $62 \%$. Pain, breathlessness and functional limitation were the most frequent symptoms. Interpersonal problems were present in $55 \%$ of the sample and contributory in $31 \%$. The corresponding figures for bereavement-related problems were $47 \%$ and $25 \%$. In the casecontrol analysis, the problems found to be risk factors for suicide were problems related to a bereavement over 1 year before death (OR 3·5, 95\% CI 1·2-10·6), and problems with accommodation (OR 5·0, $95 \%$ CI 1·1-22·8), finances $(p=0 \cdot 01)$, and retirement $(p=0 \cdot 02)$.

Conclusion. Physical illness, interpersonal problems and bereavement are commonly associated with suicide in older people, but financial, accommodation, retirement and long- term bereavementrelated problems may be more specific risk factors.

\section{INTRODUCTION}

The role of life problems in suicide varies throughout the life cycle. Older suicide victims experience fewer life events in the year before death than younger people dying through suicide, and life events preceding suicide in younger age groups are more likely to be caused by the victim's own behaviour (Heikkinen et al. 1995). One of the most frequent types of life

\footnotetext{
* Address for correspondence: Dr Daniel Harwood, Consultant in Old Age Psychiatry, Isle of Wight Healthcare NHS Trust, Older Persons Mental Health, South Block, St Mary's Hospital, Newport, Isle of Wight PO30 5TG, UK.

(Email: daniel.harwood@iow.nhs.uk)
}

event preceding suicide in older people is physical illness (Heikkinen \& Lönnqvist, 1995; Heikkinen et al. 1995; Rubenowitz et al. 2001; Duberstein et al. 2004). In $84 \%$ of a sample of older North American suicide victims physical illness was considered a stressor at the time of death (Carney et al. 1994). Serious physical illness in any organ category was found to be a risk factor for suicide in a Scandinavian casecontrol study (Waern et al. 2002). Illnesses causing functional limitation (Conwell et al. 2000), pain (Purcell et al. 1999), visual impairment, and neurological and malignant disorders (Waern et al. 2002) may be associated with a particularly high suicide risk. 
The role of life problems other than physical illness in suicide in older people has received less research attention, and has not been the subject of a case-control study in the UK. In a recent USA case-control study of life events associated with suicide (Duberstein et al. 2004), family discord, financial problems, change of employment status, and separation from a partner were found to be more frequent in people over 50 years who had died through suicide compared with an age-matched population control group. Family discord and employment change increased risk of suicide even after controlling for sociodemographic variables and mental disorder, but bereavement did not emerge as a risk factor. In a Finnish study, bereavement was no more common as a precipitant to suicide in the elderly compared with younger age groups (Heikkinen \& Lönnqvist, 1995). Most studies in this area have examined suicide risk in relation to life events in the year before death, often using interview schedules based on standardized life event scales (e.g. Paykel et al. 1971). Some contributory factors to suicide may be missed by the use of these scales, either because the factors are long term, less easy to define, related to a possible future life event [for example, worry about an imminent move into residential care (Loebel et al. 1991)] or fall outside the problem areas covered in such schedules. For this reason, in this study a definition of 'life problem' rather than 'life event' was used to examine contributory factors to suicide in older people.

We have conducted a study of life problems, including physical illness, as risk factors for suicide in older people, using psychological autopsy interviews with informants (Hawton et al. 1998). The descriptive part of the study was intended to provide a detailed picture of the nature of life problems contributing to suicide in older people in the UK. We used a control group in order to determine whether the risk factors for suicide identified in the caseseries still held when compared to an age- and sex-matched sample of non-suicide deaths.

\section{METHOD}

There were two parts to the study.

(1) A descriptive study of the life problems and physical illnesses in the year before death associated with suicide in people aged 60 years of age and older.

(2) A case-control study comparing the life problems and physical illnesses before death in a subgroup of this sample with those in an age- and sex-matched control group of people who had died through natural causes.

The Oxford Psychiatric Research Ethics Committee and the Birmingham and Solihull Research Ethics Committees approved the study.

\section{Descriptive study}

The methods of recruitment and data collection for the study have been described in previous papers (Harwood et al. 2000, 2001). The sample consisted of a consecutive series of people aged 60 years and over who had died by suicide in Berkshire, Buckinghamshire, Northamptonshire, Oxfordshire and Birmingham between 1 January 1995 and 1 May 1998. The sources of information used were coroners' inquest notes, General Practitioners' (GPs') case-notes, psychiatric records and interviews with informants.

Details of all inquests of people aged 60 years and older in which a verdict of suicide was made were collected by regular visits to the coroner's offices. Because many cases receiving a coroner's verdict of 'undetermined cause of death' or accidental death are likely to be suicides (O'Donnell \& Farmer, 1995), subjects who had received these verdicts were included in the study if a majority of the four investigators judged the death to have probably been due to suicide on the basis of information from the inquest notes (Harwood et al. 2000). Information recorded for all cases included demographic details, mode and circumstances of death, and information about problems and life events documented in the statements of relatives and other witnesses. Information on past medical history and active physical illnesses at the time of death was obtained from the GP notes.

A psychological autopsy interview was conducted with one or more key informants for as many subjects as possible by one of the investigators (D.M.J.H., Honorary Senior Registrar in psychiatry). Psychological autopsy 
interviews are an essential tool in the study of the role of life problems and physical illness in suicide, because of the limited information available from inquest records and GP notes. The key informant was the person who had been in closest contact with the subject in the year before death. Potential informants were contacted by post with the agreement of the GP of the deceased. If the first informant contacted declined to take part in the study, another informant was approached.

\section{Case-control study}

The control group was a sample of people who had died through natural causes in hospital, individually age- and sex-matched with subjects in the suicide group. Hospital administrators from two Oxford and two Birmingham general hospitals provided lists of deaths in each hospital, from which we identified patients of the same sex, and who had died at an age within 30 months either side of the age at death of a subject in the suicide group. The patient on a list whose age at death was closest to the matched suicide subject was the first control subject chosen. The medical notes of potential controls were examined for details of each patient's GP, next of kin, and medical history. The subsequent recruitment procedure was identical to that for the suicide group. We identified control subjects for 54 of the 100 suicide group subjects.

\section{The informant interview}

We aimed to conduct interviews between 6 and 12 months after each subject's death, usually in the informant's home. The interviews lasted about 3 hours (range $1 \frac{1}{2}-7$ hours) and were usually completed at a single session. The semistructured part of the interview covered the antecedents to the death, and a detailed family and personal history. A systematic set of questions elicited the presence of life problems and life events in the year before death, covering the following domains: family illness, bereavement (covering the loss of any close relative or friend), interpersonal problems with family or friends, problems related to work or retirement, financial problems, legal problems, problems related to being a victim of crime, and accommodation problems (such as worry regarding an imminent move into residential care, difficulties adjusting to new accommodation), or other housingrelated problems (e.g. structural problems). Responses to specific questions about the subjects' level of physical dependence, pain and the presence of distressing physical symptoms were also recorded. The informant was asked what he/she felt to be the most important factor contributing to the suicide. Informants were given the opportunity to mention any factors which they felt had contributed to the suicide but had not been covered in the interview. As far as appropriate and possible, the same questions were asked of informants for the suicide and control subjects. After the interviews, informants bereaved through suicide were offered the Bereavement Information Pack (Hill et al. 1997) prepared for relatives bereaved by suicide or other sudden death. Informants for the control group were offered a modified version of the same information pack. Four weeks later, the informant was telephoned to clarify any points not clear from the interview and to ascertain the impact of the interview on the informant.

\section{Coding of problems}

Using information from all sources, the interviewer recorded the problems present in the year before death for each subject, and judged whether each particular problem was likely to have contributed to the person's decision to end their life. Guidelines for the definition of a problem used in the study, and the coding of the contribution of these problems to the suicides were drawn up by the investigators, all of whom were trained psychiatrists and one of whom (K.H.) was experienced in psychological autopsy research. To be coded as such, a problem had to have definitely existed, caused difficulties in the year before death, and not be a reflection of a disturbed mental state (a delusion of poverty in a wealthy person would not be included). The full guidelines are available in the Appendix. A series of 10 consecutively recruited subjects from the suicide group was used to ascertain the inter-rater reliability of these guidelines. Detailed case summaries were written for each subject by the interviewer and were circulated to all four investigators. Using the guidelines, each investigator then coded each subject's problems and the level of contribution to death. Inter-rater reliability ratings 


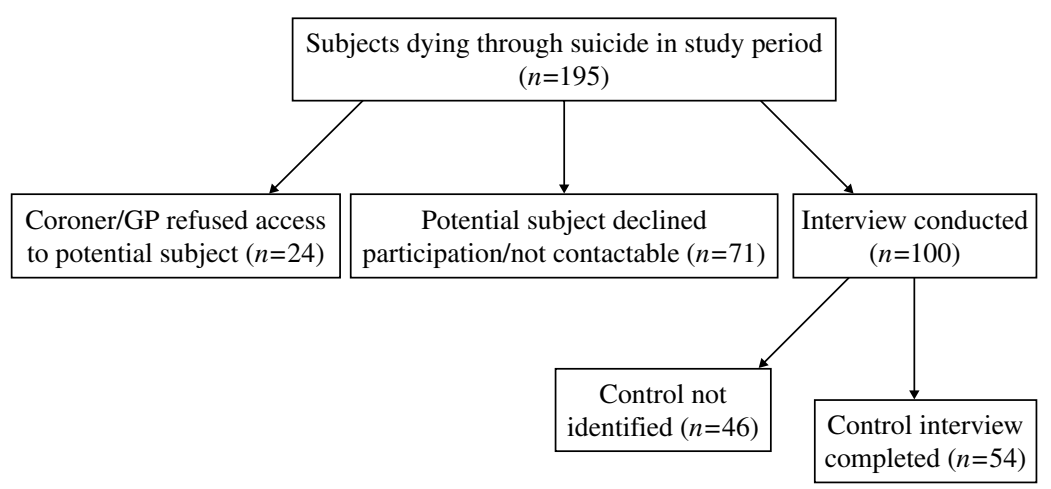

FIG. 1. Flow diagram of recruitment of informants for suicide and control subjects.

were calculated for the level of agreement between investigators. Kappa coefficient values ranged from 0.79 to $0.89(p<0.0005)$ for agreement between pairs of investigators, and for decisions about whether a problem influenced the decision to die, $0.68-0.83(p<0 \cdot 0005)$. As these values indicated good levels of agreement, for the remaining subjects the problem coding was carried out, using the guidelines, by the main investigator (D.M.J.H.) alone. In cases where multiple informants were interviewed, problems were coded by consensus at a meeting of all four investigators.

\section{Statistical analyses}

Descriptive statistics were used to analyse the characteristics of the case-series. Conditional logistic regression was used to calculate odds ratios for the effects of life problems in the case-control analyses. In this study an odds ratio is an estimate of the relative risk of suicide in those who had experienced a particular life problem relative to those who had not. Where the number of cases or controls reporting a particular life problem was zero or one, estimation of an odds ratio was not possible. As the expected values were small, the Binomial test was used to calculate $p$ values associated with these variables. The statistical packages used were SPSS for Windows version 11.5 (SPSS Inc., 2003) for the descriptive statistics and STATA 8 (StataCorp, 2003) for the conditional logistic regression analyses. Psychiatric disorder was not included as a variable in the conditional logistic regression analysis because of the high frequency of psychiatric disorder in both the suicide group $(80 \%)$ and control group $(55 \%)$.

\section{RESULTS}

\section{Descriptive study of suicide subjects}

One hundred and ninety-five subjects dying by suicide were identified in the study period. Coroners' records were viewed in all cases. A suicide verdict had been recorded in 160 cases $(82 \cdot 1 \%)$, an open verdict in 27 cases $(13 \cdot 8 \%)$ and an accidental death verdict in eight cases $(4 \cdot 1 \%)$. All but two subjects $(99 \cdot 0 \%)$ were registered with a GP at the time of their death. The GP case-notes were viewed for $159(82.4 \%)$ of these. Fig. 1 shows the drop-out of potential subjects at the different stages of recruitment. In two cases the coroner advised us not to contact relatives, in 22 cases the GP did not give consent for us to contact relatives, and in 71 cases the potential informant(s) declined to be interviewed or we were unable to contact them. Thus informant interviews were completed in 100 cases $(51 \cdot 3 \%)$. The sociodemographic characteristics of the sample were described in an earlier report (Harwood et al. 2000). The mean age of the sample was 72.2 years (range $60-91$, s.D. $=8 \cdot 42$, median $=71$ years $), 67 \cdot 7 \%$ were male, and $79.5 \%$ white and UK born. A total of $36.9 \%$ were widowed at the time of death, $34.9 \%$ married, $14.9 \%$ single, and $13.3 \%$ divorced or separated.

The prevalence of several variables in the suicide subjects with interview data and without a matched control subject was examined to look for possible selection bias. The mean ages of the 
two groups were similar $(72 \cdot 2$ and 74 years for the interview and non-interview groups respectively) and there were no statistically significant differences in the proportions of the following variables in the two groups: gender, ethnic origin, marital status of the deceased person, a coroner's verdict other than suicide, and history of contact with psychiatric services.

For subjects where informant interviews were completed, in 78 cases a single informant was interviewed, in 20 cases two informants, and in two cases more than two informants. The mean time after the deaths at which the interviews took place was 11 months (range 5-23 months). Ninety-seven $(97 \%)$ of the interviews took place face to face, two interviews were carried out over the telephone and one (with an informant who lived abroad) was completed by postal questionnaire. Ninety interviews took place in the informant's home, five at the informant's place of work, and two at the interviewer's office. The mean age of the informants for the suicide subjects was 54.9 years (range 23-85), $41.0 \%$ were male, and $75.0 \%$ had been in contact with the subject at least weekly in the year before death. Children of the deceased were the principal informants in $33.0 \%$ of cases, friends in $25.0 \%$, spouses in $17.0 \%$, siblings in $9.0 \%$, and other relatives or professionals in $16.0 \%$. These proportions did not differ to a statistically significant degree (on $\chi^{2}$ analysis) between the suicide sample for whom a matched control was identified and the sample for which this was not possible.

The rates of psychiatric and personality disorders in the subjects in this study who died through suicide have been discussed in a previous paper (Harwood et al. 2001). There was evidence of a psychiatric disorder in $77.0 \%$ at the time of death, most often depression $(63.0 \%)$. Personality disorder was present in $16.0 \%$ of cases, with an additional $28.0 \%$ showing significant personality trait accentuation.

The numbers of suicide subjects with informant interviews who experienced specific life problems in the year before death are shown in Table 1. Problems related to physical illness were the most frequent. Pain, breathlessness, and visual impairment were the most common identifiable symptoms contributing towards
Table 1. Descriptive study: life problems in the year before death in the 100 suicide subjects with an informant interview

\begin{tabular}{|c|c|c|}
\hline Life problem & $\begin{array}{c}\text { Problem } \\
\text { present } \\
(n=100)\end{array}$ & $\begin{array}{c}\text { Contributory } \\
\text { to death }\end{array}$ \\
\hline Physical illness & 82 & 62 \\
\hline Pain & 28 & 24 \\
\hline Breathlessness & 10 & 8 \\
\hline Visual impairment & 43 & 8 \\
\hline Increased physical dependence & 31 & 23 \\
\hline Interpersonal problems - total & 55 & 31 \\
\hline Conflict/poor relationship & 32 & 23 \\
\hline Worry regarding health of relative & 25 & 15 \\
\hline Separation/other & 6 & 3 \\
\hline Bereavement & 47 & 25 \\
\hline In year before death & 28 & 13 \\
\hline $\begin{array}{l}\text { Problems from bereavement } \\
>1 \text { yr before death }\end{array}$ & 19 & 12 \\
\hline Accommodation & 19 & 14 \\
\hline $\begin{array}{l}\text { Impending move into } \\
\text { residential care }\end{array}$ & 10 & 10 \\
\hline Finances & 15 & 10 \\
\hline Debt & 10 & 8 \\
\hline Loss income/other & 5 & 2 \\
\hline Social isolation & 14 & 13 \\
\hline Occupation or retirement & 13 & 6 \\
\hline Problems related to retirement & 7 & 2 \\
\hline Legal & 11 & 1 \\
\hline Victim of crime & 6 & 0 \\
\hline Involved in legal proceedings & 5 & 1 \\
\hline Other & 13 & 7 \\
\hline
\end{tabular}

suicide. Pain contributed to the subject's suicide in $24 \%$ of the sample. Three of the sample died within a month of having been given a diagnosis of a life-threatening disorder. Subcategories of other problems are listed in Table 1. Interpersonal- and bereavement-related problems were the next most frequent problem types experienced in the year before death.

The 'Other' category in Table 1 included a variety of problems that did not fit neatly into the other categories. In the seven subjects for whom one of these 'other' problems had contributed to death, two had suffered distress during very hot weather, one had experienced problems with noise and disruption due to building work next door, one had had to sell his car which led to loss of independence, one had been involved in a minor car accident, one person's key carer had retired, and one politically active man was distressed by the outcome of a local council election. 
Table 2. Case-control study. Life problems experienced in the year before death in suicide and control groups $(n=54$ in both groups)

\begin{tabular}{|c|c|c|c|c|c|c|c|}
\hline \multirow[b]{3}{*}{ Problem } & \multicolumn{7}{|c|}{ Problems for which it is possible to calculate an odds ratio using conditional logistic regression } \\
\hline & \multicolumn{2}{|c|}{ Cases $(n=54)$} & \multicolumn{2}{|c|}{ Controls $(n=54)$} & \multirow{2}{*}{$\begin{array}{l}\text { Odds } \\
\text { ratio }\end{array}$} & \multirow[b]{2}{*}{$(95 \% \mathrm{CI})$} & \multirow[b]{2}{*}{$p$ value } \\
\hline & $n$ & $(\%)$ & $n$ & $(\%)$ & & & \\
\hline $\begin{array}{l}\text { Bereavement }>1 \text { year } \\
\text { before death }\end{array}$ & 14 & $(25 \cdot 9)$ & 4 & $(7 \cdot 4)$ & $3 \cdot 50$ & $(1 \cdot 2-10 \cdot 6)$ & $0 \cdot 03$ \\
\hline Accommodation & 12 & $(22 \cdot 2)$ & 4 & $(7 \cdot 4)$ & $5 \cdot 0$ & $(1 \cdot 1-22 \cdot 8)$ & $0 \cdot 04$ \\
\hline Legal & 5 & $(9 \cdot 3)$ & 3 & $(5 \cdot 6)$ & $2 \cdot 0$ & $(0 \cdot 4-10 \cdot 9)$ & $0 \cdot 42$ \\
\hline War & 2 & $(3 \cdot 7)$ & 4 & $(7 \cdot 4)$ & $0 \cdot 50$ & $(0 \cdot 1-2 \cdot 7)$ & $0 \cdot 42$ \\
\hline Bereavement (any) & 32 & $(59 \cdot 3)$ & 29 & $(53 \cdot 7)$ & $1 \cdot 21$ & $(0 \cdot 6-2 \cdot 5)$ & 0.59 \\
\hline Social isolation & 6 & $(11 \cdot 1)$ & 7 & $(13 \cdot 0)$ & 0.83 & $(0 \cdot 3-2 \cdot 7)$ & $0 \cdot 76$ \\
\hline \multirow[t]{3}{*}{ Interpersonal } & 25 & $(46 \cdot 3)$ & 24 & $(44 \cdot 4)$ & $1 \cdot 08$ & $(0 \cdot 5-2 \cdot 4)$ & $0 \cdot 84$ \\
\hline & \multicolumn{7}{|c|}{ Problems for which it is not possible to calculate an odds ratio using conditional logistic regression } \\
\hline & \multicolumn{2}{|c|}{ Cases } & \multicolumn{2}{|c|}{ Controls } & & & \\
\hline Problem & $n$ & $(\%)$ & $n$ & $(\%)$ & & & $p$ value \\
\hline Occupation/retirement & 8 & $(14 \cdot 8)$ & 1 & $(1.9)$ & & & $0 \cdot 02$ \\
\hline Financial & 8 & $(14 \cdot 8)$ & 0 & (0) & & & $0 \cdot 01$ \\
\hline
\end{tabular}

\section{Case-control study}

The prevalence of life problems in the 54 individuals who died by suicide and the age- and sex-matched control group is shown in Table 2. Problems with occupation or retirement, financial problems, problems with accommodation, and problems arising from bereavement more than 1 year prior to death were more frequent in the suicide group. Problems related to physical illness and dependence were more frequent in the control group, as would be expected given the criteria by which the control group were selected. Therefore, physical illness was not included in the conditional logistic regression analysis. For the majority of life problems odds ratios were calculated using conditional logistic regression. However, for two of the problems this was not possible as the number of cases or controls with the problem was zero or one, and for these variables the Binomial test was used to calculate $p$ values (Table 2). For this reason, it was not possible to build a multivariate conditional logistic regression model to determine which problems significantly and independently distinguished between the case and control groups; the most important variables would have had to be left out. Instead, individual case data were examined to assess whether there was any major overlap between subjects with different problem types. This showed that four of the eight cases with occupational/retirement problems had also experienced financial problems in the year before death, but otherwise there appeared not to be significant overlap between problem types.

Problems related to social isolation were infrequently recorded in both groups. Another, more objective measure of social isolation is the frequency of social contact in the year before death, which was calculated for both groups. Using this measure, we found that 13 of the suicide group $(24 \cdot 1 \%)$ and six of the control group $(11 \cdot 1 \%)$ had had contact with a friend or relative on less than a daily basis in the year before death, but this difference failed to reach statistical significance $\left(\chi^{2}=3 \cdot 1, p=0 \cdot 08\right)$.

\section{DISCUSSION}

We have conducted the largest psychological autopsy study of suicide in older people that has been reported worldwide. In order to collect a comprehensive sample of suicides, we included deaths receiving open and accidental death verdicts where these seemed to be probable suicides. Ours is the first British study of suicide in the elderly to include informant interviews since Barraclough's (1971) survey. We included a detailed enquiry into life events and problems prior to death collecting information from a 
variety of sources. The inclusion of a control group has enabled us to study possible risk factors for suicide.

\section{Methodological issues}

The main limitation of the study was the low participation rate of potential informants in both suicide and control groups. Possible explanations for this low rate have been discussed in a previous paper (Harwood et al. 2001). Selection bias is a potential problem in a study of this type. However we found no differences in the rates of basic demographic variables in the subgroup of suicide subjects for whom a psychological autopsy interview was carried out compared to the subgroup who did not have an interview completed. Similarly, no difference in the rates of these variables was found comparing the suicide subjects for whom a control was identified and the subgroup without a control. The issue of selection bias has been discussed in more detail in a previous report (Harwood et al. 2001).

Several other types of bias can affect the validity and reliability of information obtained through psychological autopsy interview (Hawton et al. 1998). The duration of time elapsing between the death and the interview can lead to the inaccurate or selective recall of events. Some informants may lack of knowledge of aspects of the deceased subject's lifestyle. In addition, blinding of the interviewer as to whether a subject was a suicide or control was impossible. These shortcomings were minimized by adherence to a standardized interview schedule, and the use of information from GP and inquest records as well as informant interview.

Several recent studies of suicide in older people have used control groups of living people (e.g. Conwell et al. 2000; Duberstein et al. 2004). A deceased control group, such as was used in this study, minimizes asymmetry in data collection between the study and control groups (Clark \& Horton-Deutsch, 1992), but introduces different biases. For example, the high rate of physical illness in our control group meant that the role of physical health problems could not be examined in the case-control analysis, and the relatively poor physical health of the control group may have meant that this group experienced different life problems from a living control group. A higher proportion of spouses acted as informants in our control group, partly due to fewer of the suicide subjects being married. More friends were informants for the suicide group, perhaps because the coroners' notes contained details of more potential informants than hospital case-notes. These differences may have led to bias in reporting on problems in the year before death. For example, spouses may be more likely to minimize the role of marital stressors in contributing to their partner's suicide (Heikkinen et al. 1995).

Psychiatric disorder was not found to predict membership of the suicide group in an earlier case-control study on the same subjects (Harwood et al. 2001) due to the high rates of psychiatric disorder in the physically ill natural-death control group. Psychiatric disorder was not included in our conditional logistic regression analysis. For future research, a case-control study using a living control group of subjects with a depressive disorder would enable the life problems associated with suicide in depression in older people to be studied, but as noted above, a living control group introduces different biases.

Differences in the grieving process between informants in the suicide and control groups may have influenced the way informants responded. For example, control group informants may have been less likely to have been 'searching for an explanation' for the death (Barrett \& Scott, 1990) and hence less likely to remember or report all life events in the year before their relative's death. The higher rates of depression in subjects in the suicide group may have led to bias. Depressed subjects may have complained more about minor problems, which in turn might have led to the reporting of more problems by informants for the suicide group. The detailed method of coding of problems should have reduced the impact of these potential biases.

\section{Key findings}

Physical illness, bereavement, and interpersonal problems were the most frequent life problems associated with suicide, not including psychiatric illness which has been discussed in a previous paper (Harwood et al. 2001). Physical illness was a contributory factor to death in two-thirds of the cases. This finding is similar to those from other recent psychological autopsy 
studies of older people (Carney et al. 1994; Heikkinen \& Lönnqvist, 1995; Purcell et al. 1999; Rubenowitz et al. 2001; Waern et al. 2002). Pain was the most frequent specific symptom identified and contributed to the suicide of one quarter of the sample. Pain contributing to suicide was more likely to arise from osteoarthritis (12 cases) than cancer (six cases). Visual impairment and breathlessness each contributed to suicide in $8 \%$ of cases. Visual impairment has been reported as specific predictor of suicide in a recent Scandinavian case-control study (Waern et al. 2002). The most common source of breathlessness contributing to suicide was chronic obstructive airways disease. The symptoms of the common disorders of old age such as osteoarthritis, visual impairment and chronic respiratory illness may be more important in contributing to suicide than previously realized. Suicide in these disorders has been poorly researched compared with suicide in cancer and neurological illness (Stenager \& Stenager, 2000). The link between suicide and physical illness may be mediated through depressive symptoms; $60 \%$ of people in whom physical illness was a problem in the year before death also suffered from depression during the month before they died. Like Conwell and colleagues (2000) we found functional limitation to be a common factor associated with suicide. Because of the high rate of physical illness in the control group we were unable to study the role of physical illness and dependence using case-control analysis.

Epidemiological studies have confirmed a threefold risk of suicide in widowed men compared with married men (Li, 1995) and early research showed a particular increase in suicide risk in the year following spousal bereavement (McMahon \& Pugh, 1965; Bunch, 1972). However, although $28 \%$ of our suicide subjects had suffered a bereavement in the year before death [a figure higher than the $18 \%$ and $13 \%$ found in recent Californian and Finnish psychological autopsy studies respectively (Carney et al. 1994, Heikkinen \& Lönnqvist, 1995)], subjects in the suicide group were no more likely to have been bereaved in the year before death than control subjects. This mirrors the findings from a recent USA case-control study (Duberstein et al. 2004). However, problems related to a bereavement more than a year before death did predict membership of the suicide group. Ten $(71.4 \%)$ of the 14 subjects in the suicide group with these chronic bereavement-related problems had experienced a spousal bereavement more than a year prior to death. This raises the possibility that chronic distress, especially after being widowed, may be a risk factor for suicide in older people, but bereavement within the previous year is not.

This study highlights the potential importance of accommodation problems as a risk factor for suicide in older people. Accommodation issues were not identified as a risk factor in the recent USA and Swedish studies (Rubenowitz et al. 2001; Duberstein et al. 2004), possibly due to the more restrictive nature of the interview schedule used in those studies. In 10 of the 19 suicides in this study where accommodation issues were felt to be a factor which contributed to suicide, fear of an impending move into residential care triggered by increased physical dependence was the main problem. This was suggested as an important precipitant to suicide in older people by a USA group (Loebel et al. 1991) and merits more attention in future studies.

Interpersonal problems were common in both suicide and control groups and did not emerge as a risk factor for suicide. This contrasts with recent data from USA and Swedish case-control studies (Rubenowitz et al. 2001; Duberstein et al. 2004), possibly because in this study problems of a lesser severity were coded than in the latter two studies. In $15 \%$ of the sample, problems related to worry about the physical or mental health of a relative (a spouse in $8 \%$ ) contributed to suicide, highlighting a potential tragic outcome of unrecognized stress in older carers. Problems related to adjusting to retirement and financial problems (mainly debt) were more common in the suicide group than the control group. Both these problems emerged as predictors of suicide in the case-control analysis, although there was a degree of overlap between the two categories. Although financial problems are less frequently associated with suicide in older compared with younger people (Carney et al. 1994; Heikkinen \& Lönnqvist, 1995), our study suggests that financial debt may still be an important contributory factor to suicide in a subgroup of the 'young old', a finding mirrored by the recent USA study in which $12 \%$ of the suicides in people aged 50-64 years were associated with financial trouble in the year before 
death (Duberstein et al. 2004). Loss of selfworth following retirement appeared to be a contributory factor to suicide in several cases in this series.

Social isolation was mentioned as a problem in the year before death in $14 \%$ of the suicide sample, but was found to be an equally frequent problem in suicide and control groups. However, numbers were small for case-control analysis, and this could be a false-negative finding.

\section{CONCLUSIONS}

This study confirms that physical illness, interpersonal problems, and bereavement are common antecedents to suicide in older people. The study findings suggest that unresolved problems arising from bereavement more than 1 year before death are a more important risk factor for suicide in older people than a loss in the year before death. The case-control study results suggest that other less prevalent factors, such as problems related to retirement, accommodation, and financial debt, may be risk factors for suicide in older people. Life problems do not occur in isolation; a suicide is the end-point of a complex interaction of psychiatric, psychological, and demographic variables. Depression is a common mediating factor between life problems and suicide in older people (Harwood et al. 2001) and personality factors might determine how an individual reacts to life problems (Duberstein, 1995; Harwood et al. 2001). The findings of this study, along with those from other recent case-control studies of suicide, are starting to give a picture of important nonpsychiatric risk factors for suicide in older people, and may guide those who work with older people into important areas of enquiry when assessing an older person at risk of suicide. Many of the problems discussed, including some physical symptoms, unresolved grief, financial debt, worries about accommodation, and carer stress may be amenable to practical interventions which might reduce the risk of suicide in the older person experiencing those problems.

\section{ACKNOWLEDGEMENTS}

This work was supported by a MRC (UK) Project Grant awarded to Professor Robin Jacoby, Professor Keith Hawton, and Professor
Tony Hope. We thank the coroners, coroners' officers, general practitioners, and psychiatrists, who allowed us access to their records and enabled this study to take place. Helen Doll provided invaluable statistical advice. We especially thank the relatives and others who were interviewed as part of this study.

\section{DECLARATION OF INTEREST}

None.

\section{REFERENCES}

Barraclough, B. M. (1971). Suicide in the elderly. British Journal of Psychiatry 6 (Special Supplement), 87-97.

Barrett, T.W. \& Scott, T. B. (1990). Suicide bereavement and recovery patterns compared with nonsuicide bereavement patterns. Suicide and Life-Threatening Behavior 20, 1-15.

Bunch, J. (1972). Recent bereavement in relation to suicide. Journal of Psychosomatic Research 16, 361-366.

Carney, S. S., Rich, C. L., Burke, P. A \& Fowler, R. C. (1994). Suicide over 60: The San Diego study. Journal of the American Geriatrics Society 42, 174-180.

Clark, D. \& Horton-Deutsch, S. L. (1992). Assessment in absentia: the value of the psychological autopsy method for studying antecedents of suicide and predicting future suicides. In Assessment and Prediction of Suicide (ed. R. W. Maris, A. L. Berman, J. T. Maltsberger and R. I. Yufit). Guilford: New York.

Conwell, Y., Lyness, J. M., Duberstein, P., Cox, C., Seidlitz, L. \& Caine, E. D. (2000). Completed suicide among older patients in primary care practices: a controlled study. Journal of the American Geriatrics Society 48, 23-29.

Duberstein, P. (1995). Openness to experience and completed suicide across the second half of life. International Psychogeriatrics 7, 183-198.

Duberstein, P. R., Conwell, Y., Conner, K. R., Eberly, S. \& Caine, E. D. (2004). Suicide at 50 years of age and older: perceived physical illness, family discord, and financial strain. Psychological Medicine 34, 137-146.

Harwood, D. M. J., Hawton, K., Hope, T. \& Jacoby, R. (2000) Suicide in older people: mode of death, demographic factors, and medical contact before death in one hundred and ninety-five cases. International Journal of Geriatric Psychiatry 15, 736-743.

Harwood, D. M. J., Hawton, K., Hope, T. \& Jacoby, R. (2001). Psychiatric disorder and personality factors associated with suicide in older people; a descriptive and case-control study. International Journal of Geriatric Psychiatry 16, 155-165.

Hawton, K., Appleby, L., Platt, S., Foster, T., Malmberg, A. \& Simkin, S. (1998). The psychological autopsy approach to studying suicide: a review of methodological issues. Journal of Affective Disorders 50, 269-276.

Heikkinen, M. E., Isometsa, E. T., Aro, H. M., Sarno, S. J. \& Lönnqvist, J. K. (1995). Age-related variation in recent life events preceding suicide. Journal of Nervous and Mental Disease 183, 325-331.

Heikkinen, M. E. \& Lönnqvist, J. K. (1995). Recent life events in elderly suicide. International Psychogeriatrics 7, 287-300.

Hill, K., Hawton, K., Malmberg, A. \& Simkin, S. (1997). Bereavement Information Pack. For those bereaved through suicide or other sudden death. Royal College of Psychiatrists: London. Also available free on the Internet (www.rcpsych.ac.uk).

Li, G. (1995). The interaction effect of bereavement and sex on the risk of suicide in the elderly: an historical cohort study. Social Science and Medicine 40, 825-828.

Loebel, J. P., Loebel, J. S., Dager, S. R., Centerwall, B. S. \& Reay, D. T. (1991). Anticipation of nursing home placement may be a 
precipitant of suicide among the elderly. Journal of the American Geriatrics Society 39, 407-408.

McMahon, B. \& Pugh, T. F. (1965). Suicide in the widowed. American Journal of Epidemiology 81, 23-31.

O'Donnell, I. \& Farmer, R. (1995). The limitations of official suicide statistics. British Journal of Psychiatry 166, 458-461.

Paykel, E. S., Prusoff, B. A. \& Uhlenhuth, E. H. (1971). Scaling of life events. Archives of General Psychiatry 25, 340-347.

Purcell, D., Thrush, C. R. N. \& Blanchette, P. L. (1999). Suicide among the elderly in Honolulu county: a multiethnic comparative study (1987-1992). International Psychogeriatrics 11, 57-66.

Rubenowitz, E., Waern, M., Wilhelmsson, K. \& Allebeck, P. (2001). Life events and psychosocial factors in elderly suicides: a casecontrol study. Psychological Medicine 31, 1193-1202.
Shah, A. \& De, T. (1998). Suicide and the elderly. International Journal of Psychiatry in Clinical Practice 2, 3-17.

SPSS Inc. (2003). SPSS for Windows Release 11.5.2, SPSS Inc., Chicago.

StataCorp (2003). Stata Statistical Software: Release 8.0. Stata Corporation, College Station, TX.

Stenager, E. N. \& Stenager, G. (2000). Physical illness and suicidal behaviour. In The International Handbook of Suicide and Attempted Suicide (ed. K. Hawton and K. van Heeringen), pp. 405-20. Wiley: Chichester.

Waern, M., Rubenowitz, E., Runeson, B., Skoog, I., Wilhelmsson, K. \& Allebeck, P. (2002). Burden of illness and suicide in elderly people: a case-control study. British Medical Journal 324, $1355-1357$.

\section{APPENDIX}

\section{Guidelines for the coding of problems in the year before death and their influence on suicide}

This coding takes into account information from all sources i.e. suicide notes, inquest, GP, and hospital notes as well as the informant interview.

PROBLEMS are coded as follows:

0. ABSENT.

1. PRESENT. In order to be coded, a problem should have caused difficulties or distress in the year before death. Problems that started before that time but were continuing to have consequences in the last year should also be coded.

2. PROBABLE. This category should be used as little as possible and reserved for cases where, because of lack of information, it cannot be ascertained for definite whether a problem existed.

1. A problem is defined as a situation, which would cause difficulties to the average person in that position. This will exclude difficulties that were simply a reflection of a disturbed mental state, for example a delusion of poverty in a wealthy person suffering from psychotic depression. There needs to be some objective evidence that the problem actually existed, and if the person was depressed at the time of death the guiding principle should be: for the average person without depression in that position would this situation have caused difficulties?

2. Even if the situation did not cause the deceased any distress, if the problem was of the sort that would cause distress to the average person in that position, it should be coded. For example, death of a close relative or financial debt are problems and should be coded as such even if these problems were not apparently causing any distress to the deceased person.

3. Coding the same problem twice in different categories should be avoided. For example loneliness after bereavement should not be coded in the Social Isolation category as well as in the Bereavement category unless it can reasonably be thought of as a separate problem from the bereavement. For example, a man who feels lonely after his wife dies but who has a supportive social network would not be coded as having two separate problems. However someone with no living relatives or close friends who loses his wife might reasonably be coded as having problems in both the Social Isolation and Bereavement categories.

One problem can lead to another, separate problem. For example, a physical illness leading to disability and hence need for a move into a Nursing Home. It would seem reasonable to code two problems here, one under Physical Illness and the other under Accommodation.

4. Unresolved grief over a bereavement occurring more than 12 months before the subject died should only be coded as a problem if there was evidence of ongoing difficulties adapting to the loss, or specific grief symptoms in the year before death. Occasional sadness would not be enough to code the bereavement as a problem.

\section{CONTRIBUTION TO SUICIDE}

This is the influence that a particular problem had on the subject's decision to commit suicide, coded:

\section{NONE.}

1. MINOR OR MODERATE.

2. MAJOR.

3. UNCERTAIN.

This coding is more subjective than the coding of problems. The issue is: did the problem contribute to suicide in this particular person, not whether it would have contributed to suicide in a hypothetical, 'average person'. You should ask whether this particular problem, in the context of and interacting with all the other problems, as well as the person's personality, previous experience, etc., contributed to the subject's decision to commit suicide. The guiding principle is if a particular problem did not exist, but the person still had all their other problems, would the person have been any less likely to kill him/herself? So if a problem occurred in the context of a depressive illness, you should ask 'If this person did not have the problem, would he/she have been at any less risk of dying through suicide at this time?' This is obviously a subjective judgement, but the 'uncertain' category should be avoided if at all possible. 